\title{
EMPRESARIADO E AMBIENTE: ALGUMAS CONSIDERAÇÕES SOBRE A EDUCAÇÃO AMBIENTAL NO ESPAÇO ESCOLAR
}

\author{
Business community and environment: \\ some considerations about environmental education \\ in the school space
}

Carolina Messora Bagnolo1

Resumo: A Educação Ambiental é um tema que vem atraindo a atenção da sociedade, que deposita nela grande esperança no que tange à emergência de uma nova consciência socioambiental. Dada a importância da Educação Ambiental, diversos setores sociais têm se preocupado e praticado essa educação, especialmente no espaço escolar. Um desses setores que merece destaque é o empresariado que, dentro do contexto do discurso da responsabilidade social, tem levado o ambiente para além das suas fronteiras, por meio de atividades e programas de formação ambiental. Este ensaio analisa essas ações, buscando levantar algumas inquietações referentes à relação de dominação que pode se estabelecer na escola, quando a empresa tem um espaço privilegiado, em detrimento de outros setores, como o Estado, a mídia e as organizações não governamentais.

Palavras-chave: Educação ambiental. Responsabilidade social. Dominação.

\begin{abstract}
Environmental Education has been calling society's attention and it is a great hope for the emergency of a new social environmental conscience. Considering the importance of Environmental Education, several social sectors have been worrying and practiced this education, especially in the schools. One of these sectors that deserve attention is the enterprise, which within the context of the called social responsibility discourse, has taken the environment beyond its borders, through activities and programs of environmental education. This essay analyses these actions, looking for to rising some inquietudes related to the domination that can be established at schools, when the enterprise has more privileged space than other sectors, such as the State, the media and the non-governmental organizations.
\end{abstract}

Keywords: Environmental education. Social responsibility. Domination.

${ }^{1}$ Graduada em Ciências Sociais, doutoranda em Educação. Pesquisadora, grupo FORMAR - Ciências, Faculdade de Educação, Universidade Estadual de Campinas. Campinas, SP, Brasil. <carolina_mbagnolo@yahoo.com.br>

Rua José Martineli, 109

Jardim Longato - Mogi Mirim, SP

$13.806-073$ 
Bagnolo, C. M.

\section{Introdução}

O meio ambiente tem recebido um tratamento especial nos debates sobre o futuro do planeta. Mudanças climáticas, aquecimento global, derretimento das calotas polares, elevação do nível dos mares, desertificação das florestas tropicais e estratégias para redução das emissões de gás carbônico na atmosfera são alguns exemplos propalados todos os dias em jornais, revistas, telejornais, documentários, internet. Poucos questionam a veracidade desses dados, poucos duvidam da necessidade de preservação do ambiente natural ou da promoção do desenvolvimento sustentável, e todos são unânimes na afirmação de que a $\mathrm{EA}^{2}$ é uma estratégia eficaz para a emergência de uma nova consciência, pautada nas necessidades ambientais.

Esse debate, no entanto, não é novo. Remonta à década de 1960 e se intensifica na década de 1970, com o perigo crescente gerado pela Guerra Fria e a corrida armamentista, e com o grande medo de uma explosão demográfica e a consequente retomada do debate malthusiano. Nesse período, as empresas tinham pouco ou nenhum interesse pela questão ambiental, em especial as brasileiras, que estavam embriagadas pelo discurso desenvolvimentista (BAGNOLO, 2005).

Porém, ao final da década de 1980, em justaposição ao discurso do desenvolvimento, vemos emergir a ideia do desenvolvimento sustentável, que levou para o campo político a possibilidade de se unir o desenvolvimento à sustentabilidade. Por consequência, acabou por trazer, para o debate, um escopo cada vez maior de interessados na luta em prol do ambiente, desde os setores mais politizados da sociedade até aquele que, até então, era considerado o inimigo do ambiente: as empresas.

É nesse espírito, contando ainda com uma legislação ambiental cada vez mais impositiva, que vislumbramos um novo empresariado nascendo e atendendo às expectativas de uma sociedade, se não totalmente conscientizada da gravidade dos problemas ambientais, pelo menos alarmada com a crise.

Dessa sociedade mais consciente surge a pressão por produtos ecologicamente corretos, abrindo um nicho de mercado para o que se convencionou chamar de "consumidores verdes". Essa nova mercadoria exigiu novos certificados de qualidade e tecnologias limpas, sobretudo para atender as demandas do mercado europeu, exigente e consciente da problemática ambiental.

Ao mesmo tempo, as empresas perceberam que não bastava ter um produto ecológico e tecnologias limpas, uma vez que seus trabalhadores não estavam comprometidos ou conscientes em relação à importância da preservação ambiental. Nesse sentido, viu-se a necessidade de programas de EA no interior das organizações, a fim de buscar a qualidade ambiental dos produtos e do ambiente de trabalho.

Podemos perceber, do pouco que foi dito até o momento, uma mudança na mentalidade das organizações. De um discurso eminentemente capitalista e predatório, vemos a emergência de uma nova empresa, com um discurso também capitalista, mas agora preocupada

\footnotetext{
${ }^{2}$ Por ser um termo corrente, utilizaremos a sigla EA para designar Educação Ambiental. 
com o ambiente e com a sociedade. É a empresa socialmente responsável, ou com Responsabilidade Social Empresarial (RSE) ${ }^{3}$. Dentro dessa perspectiva, a partir do momento em que incorpora o social no interior da sua visão de mercado, vemos a empresa ultrapassar as suas fronteiras, por meio dos mais diversos programas sociais e ambientais.

Nesse sentido, o presente artigo busca compreender as motivações que levaram as empresas a atuarem na comunidade, em especial no campo da EA, e questionar o vigor desses programas num contexto onde as organizações são as principais, se não as únicas provedoras de uma formação ambiental na escola frente a uma desqualificação da educação pública, o que pode configurar uma nova relação de dominação no espaço escolar.

\section{A responsabilidade social e a Educação Ambiental}

A Lei n. 9.795, que dispõe sobre a Educação Ambiental (BRASIL, 1999a) estabelece, em seu artigo $3^{\circ}$, inciso $\mathrm{V}$, que cabe às empresas promoverem programas destinados à capacitação dos trabalhadores, visando a melhoria do ambiente de trabalho. Um pouco mais à frente, na seção II, artigo 13, a participação de empresas públicas e privadas é incentivada pelo Poder Público, em níveis federal, estadual e municipal, no desenvolvimento de programas de EA em parceria com a escola, com a universidade e com as organizações não governamentais.

Essa relação que se estabelece entre a escola e a empresa, no que tange à EA, obviamente não deve ser creditada somente à presença da temática na lei. Mais que isso, a inserção da EA empresarial no ambiente escolar configura-se dentro de um debate mais amplo sobre o papel das empresas na sociedade contemporânea e globalizada, e qual o discurso por elas utilizado para legitimar suas ações frente à sociedade.

O discurso amplamente utilizado e aceito é o da RSE. Para melhor entendermos esse conceito, recorremos ao Instituto Ethos (2003, [s.p]), que conceitua RSE como

[...] a forma de gestão que se define pela relação ética e transparente da empresa com todos os públicos com as quais ela se relaciona e pelo estabelecimento de metas empresariais compatíveis com o desenvolvimento sustentável da sociedade, preservando recursos ambientais e culturais para gerações futuras, respeitando a diversidade e a redução das desigualdades sociais.

Essa responsabilidade abraçada pelas organizações é, segundo o Instituto Ethos (2003), pautada em valores éticos que buscam integrar todos aqueles que, de alguma forma, colaboram no processo produtivo da empresa: os clientes, os fornecedores, a comunidade local, o governo, a gerência e os funcionários.

\footnotetext{
${ }^{3}$ Utilizaremos aqui a sigla RSE para designar Responsabilidade Social Empresarial.
} 
Bagnolo, C. M.

Contudo, esse modelo nem sempre existiu. De acordo com Rico (2004), até o início da industrialização brasileira, as ações empresariais de cunho social foram sempre pontuais, dependentes e heterogêneas, podendo classificá-las como filantropia.

Somente a partir da década de 1980, no caso brasileiro, com a intensificação do desenvolvimento tecnológico, a eliminação das fronteiras nacionais e a ressurreição dos valores liberais na economia (que culminou no que denominamos globalização econômica), que o mercado se viu impelido a mudar suas diretrizes rumo a um mercado consumidor que não está mais interessado somente em preço (RICO, 2004). Nesse momento, podemos perceber o nascimento de uma nova mentalidade empresarial, que acaba respeitando os ditames de uma nova ordem econômica e social e assumindo novas funções na sociedade. Essas novas funções decorrem tanto da exigência do mercado externo, como também da pressão da sociedade civil por produtos de qualidade e socialmente responsáveis.

Para atender a esta nova demanda, as organizações empresariais começaram a promover um discurso politicamente correto, implantando, junto à comunidade, projetos sociais que podem gerar ganhos na condição do trabalhador e da população envolvida, podem se tornar um instrumento de marketing social (RICO, 2004) ${ }^{4}$, como, também, uma política de dominação - caso que trabalharemos neste artigo.

Rico (2004, p. 74) aponta ainda uma das consequências de um projeto social bemsucedido: é a construção de uma imagem positiva que se dá por meio das ações que a empresa promoveu em seu entorno, ou seja, "seu reconhecimento institucional, comunitário e social". Isso porque há uma preocupação, por parte do empresariado, de que suas práticas de RS sejam percebidas pelo consumidor e que essas práticas reforcem ainda mais a sua marca.

Portanto, trata-se de uma questão estratégica o investimento na área social, pois as empresas ao serem reconhecidas como socialmente responsáveis tendem a conseguir diferenciais de competitividade e uma vez tendo a imagem valorizada, podem aumentar a motivação dos funcionários no trabalho e atrair um número maior de parceiros dispostos a colaborar com a causa social (RICO, 2004, p.75).

\section{A empresa socialmente responsável e as escolas}

As ações empresariais no âmbito da escola brasileira caminham juntas com a consolidação do neoliberalismo enquanto ideologia dominante no país. Dentro da perspectiva neoliberal, o Estado é colocado como ineficiente e ineficaz. No contexto educacional não deixa de ser diferente. A crise no sistema educacional dá-se pelo caráter deficitário do Estado no geren-

\footnotetext{
${ }^{4}$ Kotler (1978, p. 287), autor corrente e clássico no campo da Administração de Empresas, define marketing social como "[...] o projeto, a implementação e o controle de programas que procuram aumentar a aceitação de uma idéia social num grupo-alvo. Utiliza conceitos de segmentação de mercado, de pesquisa de consumidores, de configuração de idéias, de comunicações, de facilitação de incentivos e a teoria da troca, a fim de maximizar a reação do grupo-alvo".
} 
ciamento das políticas públicas educacionais, e novas propostas de ajuda, advindas do meio empresarial, surgem neste debate. Esse embate entre público e privado na educação evidenciase em práticas como: escolas cooperativas, vale-educação, implantação e avaliação de sistemas educacionais, e parcerias para o financiamento dos serviços educacionais (SOUZA, 2000).

Dentre as parcerias incentivadas pelo poder público, destaca-se a relação empresa e escola. Essa estratégia é tida como a grande solucionadora do caos que aflige o sistema educacional brasileiro. Se os empresários brasileiros são tão vitoriosos e superaram tantos obstáculos, estes só têm a colaborar para a vitória, eficiência e eficácia da educação brasileira, por meio de mecanismos de controle e avaliação da qualidade dos serviços educacionais, subordinação da educação às necessidades do mercado $^{5}$ e, sobretudo, doação de recursos financeiros às escolas adotadas.

Dentre as inúmeras possibilidades de parcerias que se estabelecem entre as empresas e as escolas, Souza (2000) menciona: as empresas que mantém sistema de ensino próprio (para funcionários ou filhos destes); as que mantêm convênios com equipes de escolas particulares; e as que colaboram com o sistema público de ensino, a partir de diversas formas de articulação. É dentro deste último grupo que se situa essa pesquisa.

\section{O estímulo às parcerias}

Os últimos governos estaduais vêm estimulando parcerias entre empresas e escolas da rede. Esta iniciativa teve início, particularmente, no governo Quércia (1987-1990), quando foi lançado o programa "Adote uma escola". Posteriormente, no governo Fleury (1990-1994), foi divulgado um documento intitulado "Programa de parceria empresa-escola pública", que possuía, como um de seus objetivos, a ampliação da participação de empresários na gestão do ensino público. No governo Covas (1995-2000), foram registradas novas disposições no Diário Oficial, onde se colocava, entre outras, a necessidade de se descentralizarem e se desconcentrarem ações, de forma a favorecer a autonomia da gestão em nível local (SOUZA, 2000).

Em continuidade a essas propostas, o governo José Serra (2007-2010) decide ampliar essas parcerias, pretendendo chegar a quinhentas escolas participantes destes projetos. Depois de um ano de parceria, as empresas recebem o selo de Empresa Educadora (SÃO PAULO, 2007). Dentre as possibilidades de parceria estão, sobretudo, melhorias na estrutura física das escolas. O aprendizado, a educação continua sendo, nas palavras da então secretária Maria Helena Guimarães de Castro, responsabilidade do Estado.

É um projeto que já deu certo. Agora iremos ampliá-lo. Visamos melhorar a qualidade do ensino e o aproveitamento escolar dos alunos. $\mathrm{O}$ Estado continua responsável pelo aprendizado, como não poderia ser diferente, mas a responsabilidade social das empresas entra em jogo. (SÃO PAULO, 2007)

\footnotetext{
${ }^{5}$ Os Parâmetros Curriculares Nacionais (BRASIL, 1999b) enfatizam, com grande veemência, a economia, colocando a educação para um fim: o trabalho e a produção econômica. 
Bagnolo, C. M.

Os argumentos utilizados para que estas parcerias se fortaleçam e ganhem legitimidade, para além da ineficiência do Estado, está no discurso de autonomia que vem acoplado aos projetos governamentais. Delega-se, a cada escola, a responsabilidade de viabilizar recursos para melhorar suas condições. Daí entra o empresariado, segmento mais convocado para trazer os critérios de organização empresariais para dentro dos muros da escola (GENTILI, 1996; SOUZA, 2000).

Percebemos, assim, que esta nova filosofia empresarial ganha adeptos a cada dia, como também novos projetos surgem ao sabor do mercado. Mas o que chama atenção é que a EA praticada pelas empresas escapou ao âmbito doméstico e chegou à comunidade, por meio das mais diferentes atividades: projetos de inclusão social, de inclusão no mercado de trabalho e, o que nos interessa neste artigo, programas de formação ambiental, ou de EA, na comunidade escolar.

A atuação dessas organizações empresariais no ambiente escolar está se tornando muito comum, e até mesmo chegou-se ao ponto de naturalizarmos essa preocupação e ação das empresas. Essas atividades são bem-vindas para os educadores e diretores das escolas e há uma mobilização crescente desse grupo para que os projetos de EA empresarial cheguem às escolas e sejam implantados. Afinal, é unânime o pensamento de que é interessante que a empresa atue na sociedade como uma forma de compensar os possíveis problemas decorrentes de sua prática produtiva.

As ações empresariais são variadas e dependem da estrutura dos programas, do tipo de atividade que estão propondo e da disposição em estabelecer vínculos com a escola. É muito comum as empresas elaborarem materiais didáticos para o uso do professor na sala de aula, tais como: cartilhas, livrinhos, jogos educativos com teor ecológico, filmes, para citarmos alguns exemplos. Outras atividades muito comuns são os concursos de redação, ou de artes, com caráter ecológico, promovidos pelas empresas. Destes, temas como aquecimento global, floresta amazônica, mata atlântica, animais em extinção, reciclagem e uso da água são os mais comuns.

Excursões no interior da organização também são muito utilizadas, especialmente naquelas que possuem atrativos como parques e reservas. Nesses, as crianças, os adolescentes e os professores passam o dia, com atividades lúdicas e recebendo informações pertinentes sobre o meio ambiente e a ações destrutivas ou construtivas do homem. Quando a empresa não possui essas reservas ou parques, propõe às escolas plantio coletivo de árvores, em grandes avenidas ou próximo a rios importantes da cidade ou bairro em que a escola está inserida. E, por último, e não menos importante, a proposição de gincanas entre escolas da comunidade, como, por exemplo, jogos para arrecadação de papéis para reciclagem ou lixo para cooperativas de reciclagem. Esses exemplos delineiam a atuação direta da empresa na escola. Outra forma de atuação é por meio de práticas de formação continuada do professor, que se configura como uma ação mais duradoura entre empresa e escola, por intermédio do educador.

Tendo em mente que "[...] a concepção de Educação Ambiental dos professores e, conseqüentemente, a prática que realizam, decorre das múltiplas influências que as diversas instituições e suas práticas exercem sobre eles" (FRACALANZA, 2003, p. 4), preocupamonos aqui com as concepções de sociedade, educação, ambiente, ciência, que a prática empresarial traz para o ambiente escolar, por meio das ações de EA. E ainda, independente da visão que é transmitida, o problema de esse ser, muitas vezes, o principal canal de formação de educadores ambientais no espaço escolar. 
Tendo como pressuposto que há múltiplas ações de EA, cabe-nos aqui diferenciá-las, buscando, na literatura, algumas categorias a fim de compreendermos a importância que determinada modalidade ou tendência tem para a visão de EA que é transmitida aos professores $\mathrm{e}$, consequentemente, a seus educandos.

Fracalanza (2003), utilizando-se de uma classificação de Sorrentino (1997), destaca as principais correntes de EA:

. Conservacionista;

- Educação ao ar livre;

- Gestão ambiental;

. Economia ecológica.

Cada corrente destacada acima, segundo Fracalanza (2003), possui concepções diferenciadas entre si, que são determinadas, sobretudo, pelo tipo de instituição que a pratica (ONG, mídia, escola, empresa).

Já Brügger (1994) delineia duas grandes modalidades de EA:

. Uma primeira tendência seria aquela fornecida pelas ciências humanas e sociais, em que os fatores sócio-históricos se sobressaem aos fatores técnicos ou naturais da questão ambiental.

- Outra, em que a problemática ambiental é tratada exclusivamente sob a ótica das dimensões naturais e técnicas, negligenciando os fatores sociais e políticos.

Para Brügger (1994), essa segunda tendência tem prevalecido porque houve uma fragmentação do saber que empobreceu o diálogo entre as ciências humanas e as ciências naturais e exatas. Para essa autora, a ausência desse diálogo deve ser superada para que possamos dar conta da problemática ambiental, ainda mais num contexto onde o saber instrumental tem prevalecido e predominado na segunda tendência destacada acima.

Lima (2002) aponta duas tendências no vasto campo da EA: a conservadora e a emancipatória - entendendo estes dois opostos como tipos ideais ${ }^{6}$, no sentido que Max Weber dá ao termo.

A EA conservadora caracteriza-se, sinteticamente, por uma visão fragmentada e reducionista, por uma leitura individualista e comportamentalista, além de uma despolitização do debate ambiental, em consonância com a banalização da noção de cidadania e participação social. Já a vertente emancipadora caracteriza-se por uma visão que abarca a complexidade e a multidimensionalidade da questão ambiental, por meio de uma atitude crítica que tem a democracia e a participação cidadã como pré-requisito da sustentabilidade (LIMA, 2002).

\footnotetext{
${ }^{6}$ De acordo com Cohn (1982, p. 8), um dos grandes estudiosos da obra weberiana, "trata-se de um recurso metodológico para ensejar a orientação do cientista no interior da inesgotável variedade de fenômenos observáveis na vida social. Consiste em enfatizar determinados traços da realidade - por exemplo, aqueles que permitam caracterizar a conduta do burocrata profissional e a organização em que ele atua - até concebê-los na sua expressão mais pura e conseqüente, que jamais se apresenta assim nas situações efetivamente observáveis". É importante ressaltar que todos os autores citados, que enveredam no debate das tendências e modalidades de EA, acabam por sistematizá-las metodologicamente na forma de tipos ideais, pois dificilmente serão encontradas na realidade na sua forma mais pura ou sem interferência e influências de outras tendências e/ou modalidades.
} 
Bagnolo, C. M.

Lima (2002) aponta uma terceira tendência, que ele denomina conservadorismo dinâmico. Este conceito, também trabalhado por Guimarães (1998), “[...] opera por mudanças aparentes e parciais nas relações entre sociedade e o ambiente enquanto conserva o essencial. $\mathrm{Na}$ verdade, a própria racionalidade de sua ação apóia-se na idéia de antecipar mudanças cosméticas a fim de garantir que não haja mudanças" (LIMA, 2002, p.125).

Esta tendência da EA, na concepção de Lima (2002), torna-se um grande obstáculo para a transformação socioambiental, devido à sua ampla visibilidade na mídia e o uso da linguagem científica, que transmite uma visão objetiva da realidade.

Já Amaral (2006) resume as tendências em EA da seguinte forma:

- Adestramento ambiental;

. Desenvolvimento sustentável;

. Ecologismo radical;

- Crítica.

A primeira tendência, de adestramento ambiental, advém do teor instrumental e pouco crítico da prática educativa. Tenta-se, nessa perspectiva político-filosófica, desenvolver posturas e atitudes corretas nos educandos, sem preocupar-se com os pressupostos sociais, políticos e econômicos. Há uma visão utilitarista e antropocêntrica, onde a ciência e a tecnologia estão a serviço da resolução dos problemas (AMARAL, 2006). Pode-se identificar uma similaridade entre essa tendência e aquela que Lima (2002) denominou de conservadora.

A segunda tendência, do desenvolvimento sustentável, preconiza o equilíbrio entre ambiente e desenvolvimento econômico, sem que profundas transformações ocorram, o que se assemelha ao que Lima (2002) chama de conservadorismo dinâmico. Como mostra Amaral (2006, p. 9), "nessa perspectiva, sociedade e cultura se pasteurizam e subordinam-se irremediavelmente à economia e aos interesses ambientais". Da mesma forma que na primeira tendência, há uma visão antropocêntrica, porém atenuada, e uma certeza de que a ciência e a técnica trarão soluções para o problema ambiental.

O ecologismo radical, terceira tendência analisada por Amaral (2006, p. 9), "preconiza uma transformação completa dos atuais padrões de relação entre ser humano e restante da natureza [...]". Nessa tendência, em contraposição total às anteriores, a ciência e a técnica são as grandes culpadas pela crise em que vivemos, assim como o capitalismo e suas formas de exploração. Para tanto, propõe uma ética preservacionista e um retrocesso total nos padrões atuais de civilização.

A última tendência, do pensamento crítico, aproxima-se do modelo emancipatório anunciado por Lima (2002) e

[....] consubstancia-se em um conjunto de diretrizes programáticas e metodológicas que procuram oferecer uma alternativa coerente e consistente às críticas e objeções que traz às demais tendências, comprometendo-se a revelar plena e autenticamente o ambiente em suas múltiplas facetas. (AMARAL, 2006, p. 10)

Ainda segundo Amaral (2006), suas principais críticas e objeções às demais tendências de EA são variadas, e podemos resumir nos seguintes tópicos:

- Antropocentrismo e utilitarismo exagerados; 
- Cientificismo exagerado;

- Individualização da responsabilidade ambiental;

- Supremacia do ambiente sobre a vida humana;

- Pouca importância dada aos poderes políticos e econômicos;

- Dissociação entre crise ambiental e crise de civilização;

- Inviabilidade do desenvolvimento sustentável em face das contradições existentes;

- Imposição de uma nova ética;

- Fragmentação, compartimentação e reducionismo da EA, assim como a dissociação entre EA e educação em geral.

Como resposta a estas objeções, Amaral (2006) sintetiza algumas propostas da tendência do pensamento crítico:

. Utilização de critérios de relevância social e cultural na seleção de conteúdos;

- Incorporação do cotidiano do aluno e de seus conhecimentos prévios;

- Centralizar o processo de ensino-aprendizagem no estudo dos fenômenos, para, posteriormente, ocorrer a formulação de conceitos;

- Tratar os assuntos de acordo com as manifestações espaço-temporais compatíveis com o desenvolvimento cognitivo dos educandos;

- Respeito às formas não cientificas de conhecimento;

- Necessidade de uma contextualização histórica do conhecimento científico;

- Desvendar relações entre ciência e técnica;

. Buscar a interdisciplinaridade;

. Entender o ambiente como algo em total transformação, num equilíbrio dinâmico;

- Buscar formas de atenuamento do antropocentrismo e utilitarismo;

. Entender a questão ambiental dentro da complexidade que a temática exige: aspectos históricos, físicos, biológicos, sociais, econômicos, filosóficos e políticos;

- Favorecer uma maior flexibilidade curricular.

Essas correntes destacadas acima servem para nos alertar para as práticas de EA que são realizadas no âmbito escolar e, ainda, para podermos analisar, de uma forma crítica, a atuação dos programas de formação ambiental das empresas.

No nosso entender, a inserção do debate ambiental proporcionado pelos programas de formação das empresas é interessante e merece destaque, uma vez que proporciona à escola algum tipo de informação e, até mesmo, debate sobre a questão ambiental. Sabemos também que essa prática está respeitando as novas dinâmicas éticas e morais das organizações modernas, assim como torna-se instrumento de marketing social, gerando ganhos financeiros. Contudo, o que nos preocupa é o fato de essa prática educativa ser a predominante no espaço escolar, em detrimento de ações financiadas por outras organizações da sociedade ou, até mesmo, do Estado. E ainda, preocupa-nos a tendência e/ou modalidade predominante no campo da EA empresarial.

Levando em conta a breve descrição que fizemos de algumas atividades frequentes das empresas, podemos tentar uma classificação provisória, que merece também maior aprofundamento empírico: em sua grande maioria, podemos afirmar que essas ações se encaixam no que Amaral (2006) classificou como adestramento ambiental, muito embora percebamos, também, a presença da tendência do desenvolvimento sustentável. É importante salientar que as empresas praticam efetivamente uma EA, com características que podemos considerar como 
Bagnolo, C. M.

conservadoras, porém com um posicionamento distante daquele almejado por uma corrente crítica da EA.

Um primeiro limite da EA empresarial está na pouca participação dos educadores e educandos na elaboração, reelaboração e efetivação dos projetos propostos. Em sua grande maioria, o professor acaba apenas repassando as informações aos alunos que, mecanicamente, reproduzem o que está sendo posto pela organização empresarial.

Ao mesmo tempo, os temas propostos ou os projetos elaborados não partem do cotidiano do aluno, buscando-se, sempre, temas "macro" ambientais, que acabam despolitizando e gerando uma "a-criticidade" do contexto em que esses jovens vivem, sobretudo porque, geralmente, são moradores das regiões mais pobres da cidade e, por coincidência ou não, nas redondezas das empresas. Assim, questões como a destinação do lixo doméstico, poluição de córregos e rios, o próprio ambiente escolar, o consumo e suas consequências são abandonadas em função de temas macro, que são importantes, mas não fazem parte da realidade vivida pelo aluno. Assim, podemos afirmar que há uma desvinculação quase sempre presente entre os problemas ambientais e a realidade social. Mais uma vez, uma despolitização do fazer do educador ambiental e do educando.

Alguns poderiam nos questionar sobre a nossa ingenuidade em pensar que as empresas agiriam de forma diferente, propondo às escolas uma EA crítica e transformadora. Embora não possamos descartar a possibilidade de isso ocorrer, entendemos que a prática empresarial proposta está em consonância com o modelo de sociedade que enseja. No nosso entender, a EA empresarial apenas reproduz a visão de sociedade, de ambiente, de ciência, entre outras, das organizações empresariais, seja ela qual for.

O que ocorre - e aqui recorremos ao texto de Soares (2004) - é que, na fala da RS, estão presentes três discursos: o explicitado; o discurso pronunciado reservadamente; e o discurso não dito.

No discurso explicitado, a empresa assume uma postura ética e não restringe seus esforços à sua função econômica. Para Soares (2004), esse discurso deixa transparecer que a organização está atendendo aos apelos da sociedade, escondendo o real sentido da mudança. Já no discurso explicitado reservadamente, Soares (2004) destaca a RS como uma estratégia competitiva, para usarmos termos da ciência administrativa. Este discurso destaca a competitividade acirrada do mundo globalizado como mola propulsora de ações de RS.

O discurso não dito da RS tem o objetivo de transformar o interesse particular de uma organização capitalista (e, consequentemente, lucrativa), em um interesse da coletividade, para conferir legitimidade ao que não é legitimo. Essa constatação nos leva a Lima (2002), que afirma que uma "sustentabilidade de mercado" não responde à crise social, pois a racionalidade presente no mercado é orientada para a concentração de riqueza, e não sua distribuição. $O$ mercado é, na verdade, um eficiente instrumento de alocação de recursos, mas péssimo gestor das desigualdades sociais.

Percebemos que, muitas vezes, este é o único canal de formação ambiental nas escolas. E diante das exigências governamentais, que pedem que a questão ambiental seja inserida, transversalmente, no currículo escolar, essa formação ambiental pode ser assimilada, muitas vezes, de forma não crítica, e inserida nas salas de aula, sem uma problematização maior da problemática ambiental. Neste sentido, as empresas acabam se tornando "as instituições das instituições", como bem mostra Soares (2004), atendendo a uma expectativa das escolas (e, 
por que não, do governo) suprindo, em parte, a deficiência das demais instituições em estabelecer vínculos com a escola.

Quando dizemos que as empresas se tornam "as instituições das instituições", estamos afirmando que uma nova relação de poder se estabelece, onde outros agentes - universidades, organizações não governamentais e, especialmente, o Estado, por meio de políticas de formação continuada na área ambiental - ganham menos importância, sobressaindo a atuação empresarial.

O que é interessante notar é que o discurso e a prática da RS surgem num contexto em que as empresas detinham liberdade total para agir, com algumas restrições no interior de suas fronteiras (sobretudo no que tange às relações trabalhistas) e numa total incapacidade de pensar a sociedade como a maior beneficiada de ações responsáveis, como também a maior prejudicada frente às práticas irresponsáveis. A noção de responsabilidade empresarial nasce, neste sentido, como uma forma de limitar a ação e, por que não, a dominação das empresas, mas hoje, sob o discurso da responsabilidade, acaba agindo da mesma forma, fixando regras e novas condutas, assim como ditando o que é correto ou não no que tange à questão ambiental e, ainda, à educação, âmbito que foge (ou deve fugir) totalmente ao escopo das leis do mercado.

\section{Considerações finais}

As ações sociais empresariais, mais especificamente as ações de RS, trouxeram uma nova consciência para o mundo dos negócios, amenizando (e não solucionando, é importante frisar) os efeitos nocivos do modo de produção capitalista. De um campo em que tudo se podia, chegamos a um campo no qual as ações empresariais passaram a ser delimitadas por uma ética compartilhada por todos - a ética da responsabilidade.

Por outro lado, vimos que, se a noção de responsabilidade veio para limitar a ação das empresas, ao mesmo tempo, o uso do discurso da RS pode se tornar uma forma de dominação que a empresa estabelece sobre seus funcionários, clientes, consumidores e, sobretudo, a comunidade.

Esta dominação estabelecida tem algumas facetas importantes a serem comentadas. Uma primeira faceta que merece destaque é a desqualificação do poder público disseminada pela iniciativa privada. Para Paoli (2002), a fala do empresariado recai na falência do Estado em suprir as necessidades da sociedade e, por isso, há uma responsabilização privada do social, trazendo, para as empresas, as responsabilidades que deveriam estar divididas pelos diferentes atores sociais. Seguindo a linha de pensamento de Paoli (2002), acrescentando ainda Dagnino (2004), a noção de responsabilidade social, onde se inserem os programas de EA promovidos pela empresa, tem como princípio básico a adoção de uma "perspectiva privatista e individualista, capaz de substituir e redefinir o significado coletivo da participação social" (DAGNINO, 2004, p. 102). Essa despolitização é conflitante com aquilo que acreditamos ser uma EA emancipadora ou crítica, e ainda reflete uma relação de poder quando desqualifica o outro como provedor do bem-estar social.

Uma segunda faceta, não menos importante, decorrente desta despolitização da questão social e também socioambiental, está na naturalização da ação empresarial na comunidade e, ainda, na tolerância frente aos problemas que essas organizações podem, porventura, ocasi- 
Bagnolo, C. M.

onar. Esses problemas - que podem ser desde o não cumprimento ocasional das leis trabalhistas até a poluição do rio mais próximo à empresa - podem passar despercebidos ou, até mesmo, podem ser tolerados, uma vez que a empresa está realizando a RS e cumprindo seu papel social. Isso configura, no nosso entender, uma relação de dominação.

Uma terceira e última faceta, no que tange à EA, é interessante mencionar: a atuação das empresas - pois, de qualquer forma, está levando às escolas um debate que nem sempre é privilegiado. Porém, preocupam-nos as concepções de ambiente, ciência, sociedade e educação que estão atreladas à prática de formação empresarial, pois, em sua grande maioria, a ação de EA proveniente dessas diferentes visões é incompatível com o pensamento crítico e emancipatório. Assim, quando a EA torna-se monopólio de uma empresa, educadores e educandos acabam restritos a uma única visão de mundo, fragilizando o debate profícuo e necessário que poderia existir entre mercado, sociedade, governo e organizações sociais.

\section{Referências}

AMARAL, I. A. A educação ambiental nos currículos escolares. Campinas: Faculdade de Educação, Unicamp, 2006. [Trabalho não publicado].

BAGNOLO, C. M. Produção intelectual em qualidade de vida na América Latina. 2005. 169f. Dissertação (Mestrado em Sociologia) - Instituto de Filosofia e Ciências Humanas, Universidade Estadual de Campinas, Campinas, 2005.

BRASIL. Lei n. 9.795, de 27 de abril de 1999. Dispõe sobre a educação ambiental, institui a Política Nacional de Educação Ambiental e dá outras providências. Diário Oficial da União, Brasília, DF, 1999a.

Ministério da Educação. Secretaria de Educação Média e Tecnológica. Parâmetros

Curriculares Nacionais: Ensino Médio. Brasília: MEC, 1999. 4 v.

BRÜGGER, P. Educação ou adestramento ambiental? Santa Catarina: Letras Contemporâneas, 1994.

COHN, G. (Org.). Max Weber: sociologia. 2. ed. São Paulo: Ática, 1982.

DAGNINO, E. Sociedade civil, participação e cidadania: de que estamos falando?. In: MATO, D. (Coord.). Politicas de ciudadania y sociedad civil en tiempos de globalización. Caracas: FACES, Universidad Central de Venezuela, 2004. p. 95-110. 
Empresariado e ambiente: ...

FRACALANZA, H. A educação ambiental nas escolas: problemas e perspectivas. Revista Contestado e Educação, n. 6, 2003. Disponível em: < http://www.pg.cdr.unc.br/ revistavirtual/numeroseis>. Acesso em: 10 abr. 2006.

GENTILI, P. Neoliberalismo e educação: manual do usuário. In: GENTILI, P.; SILVA, T. T. (Orgs.). Escola SA. Brasília: CNTE, 1996. p. 9-49.

GUIMARAES, R. P. Modernidad, medio ambiente y ética: un nuevo paradigma de desarrollo. Ambiente e Sociedade, Campinas, v. 1, n. 2, p. 5-24, 1998.

INSTITUTO ETHOS. Responsabilidade social empresarial para micro e pequenas empresas. São Paulo: Instituto Ethos/Sebrae, 2003.

KOTLER, P. Marketing para organizações que não visam lucro. São Paulo: Atlas, 1978.

LIMA, G. F. C. Crise ambiental, educação e cidadania: os desafios da sustentabilidade emancipatória. In: LOUREIRO, C. F. B.; LAYRARGUES, P.; CASTRO, R. S. (Orgs.).

Educação ambiental: repensando o espaço da cidadania. São Paulo: Cortez, 2002. p. 109-141.

PAOLI, C. Empresas e responsabilidade social: os enredamentos da cidadania no Brasil. In: SANTOS, B. S. (Org.). Democratizar a democracia: os caminhos da democracia participativa. Rio de Janeiro: Civilização Brasileira, 2002. p. 373-418.

RICO, E. M. A responsabilidade social empresarial e o Estado: uma aliança para o desenvolvimento sustentável. São Paulo em Perspectiva, São Paulo, v. 14, n. 18, p. 73-82, 2004.

SÃO PAULO. Secretaria de Educação. SP vai atrás de empresas que adotem escolas, 2007. Disponível em: <http://www.saopaulo.sp.gov.br/spnoticias/lenoticia.php?id=90363>. Acesso em: 20 jan. 2010.

SOARES, G. M. P. Responsabilidade social corporativa: por uma boa causa!? RAE Eletrônica, v. 3, n. 2, 2004. Disponível em: <http: //www.era.com.br/eletrônica/index. cfm?FuseAction=Artigo\&ID=1666\&Seção=FOR.ESTCRI\&Volume=3\&Numero=2\&Ano=2004> . Acesso em: 16 abr. 2007

SORRENTINO, M. Vinte anos de Tbilisi, cinco da Rio 92: a Educação Ambiental no Brasil. Debates Socioambientais, São Paulo, v. 2, n. 7, p. 3-5, 1997.

SOUZA, S. M. Z. L. Parceria escola-empresa no estado de São Paulo: mapeamento e caracterização. Educação e Sociedade, Campinas, v. 21, n. 70, p. 171-188, 2000.

Artigo recebido em dezembro de 2009 e aceito em fevereiro de 2010. 